\title{
Functional Long-Term Outcome after Left- versus Right-Sided Intracerebral Hemorrhage
}

\author{
Vanessa D. Beuscher ${ }^{\mathrm{a}} \quad$ Joji B. Kuramatsu ${ }^{\mathrm{a}}$ Stefan T. Gerner ${ }^{\mathrm{a}}$ \\ Julia Köhn $^{\text {a Hannes Lücking }}{ }^{b}$ Stephan P. Kloska ${ }^{b}$ Hagen B. Huttner ${ }^{a}$ \\ ${ }^{a}$ Department of Neurology, and ${ }^{b}$ Department of Neuroradiology, University of Erlangen-Nuremberg, \\ Erlangen, Germany
}

\section{Key Words}

Intracerebral hemorrhage $\cdot$ Hemisphere $\cdot$ Location .

Outcome $\cdot$ Epidemiology

\begin{abstract}
Background and Purpose: Hemispheric location might influence outcome after intracerebral hemorrhage (ICH). INTERACT suggested higher short-term mortality in right hemispheric $\mathrm{ICH}$, yet statistical imbalances were not addressed. This study aimed at determining the differences in long-term functional outcome in patients with right- vs. leftsided ICH with a priori-defined sub-analysis of lobar vs. deep bleedings. Methods: Data from a prospective hospital registry were analyzed including patients with $\mathrm{ICH}$ admitted between January 2006 and August 2014. Data were retrieved from institutional databases. Outcome was assessed using the modified Rankin Scale (mRS) score. Outcome measures (long-term mortality and functional outcome at 12 months) were correlated with ICH location and hemisphere, and the imbalances of baseline characteristics were addressed by propensity score matching. Results: A total of 831 patients with supratentorial ICH (429 left and 402 right) were analyzed. Regarding clinical baseline characteristics in the unadjusted overall cohort, there were differences in disfavor of right-sided ICH (antiplatelets: $25.2 \%$ in left ICH vs. $34.3 \%$ in right ICH; $p<0.01$; previous ischemic stroke: $14.7 \%$ in left ICH
\end{abstract}

\section{KARGER}

(C) 2017 S. Karger AG, Basel

E-Mail karger@karger.com

www.karger.com/ced vs. $19.7 \%$ in right $\mathrm{ICH} ; p=0.057$; and presence/extent of intraventricular hemorrhage: $45.0 \%$ in left $\mathrm{ICH}$ vs. $53.0 \%$ in right ICH; $p=0.021$; Graeb-score: 0 [0-4] in left ICH vs. 1 [0-5] in right $\mathrm{ICH} ; p=0.017)$. While there were no differences in mortality and in the proportion of patients with favorable vs. unfavorable outcome (mRS 0-3: 142/375 [37.9\%] in left ICH vs. $117 / 362$ [32.3\%] in right ICH; $p=0.115$ ), patients with leftsided $\mathrm{ICH}$ showed excellent outcome more frequently (mRS 0-1: 64/375 [17.1\%] in left ICH vs. 43/362 [11.9\%] in right ICH; $p=0.046$ ) in the unadjusted analysis. After adjusting for confounding variables, a well-balanced group of patients ( $n=360 /$ hemisphere) was compared showing no differences in long-term functional outcome (mRS 0-3: 36.4\% in left ICH vs. $33.9 \%$ in right $\mathrm{ICH} ; p=0.51$ ). Sub-analyses of patients with deep vs. lobar $\mathrm{ICH}$ revealed also no differences in outcome measures (mRS 0-3: 53/151 [35.1\%] in left deep ICH vs. 53/165 [32.1\%] in right deep ICH; $p=0.58$ ). Conclusion: Previously described differences in clinical end points among patients with left- vs. right-hemispheric ICH may be driven by different baseline characteristics rather than by functional deficits emerging from different hemispheric functions affected. After statistical corrections for confounding variables, there was no impact of hemispheric location on functional outcome after $\mathrm{ICH}$.

(c) 2017 S. Karger AG, Basel

V.D.B. and J.B.K. contributing equally.

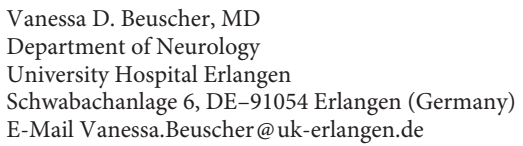

Schwabachanlage 6, DE-91054 Erlangen (Germany) 


\section{Introduction}

Spontaneous intracerebral hemorrhage (ICH) accounts for about $15 \%$ of strokes and is associated with high mortality, severe disability, and unfavorable functional outcome $[1,2]$. The hemispheric location of ischemic and hemorrhagic stroke and its impact on clinical end points has only been studied insufficiently, yet this field is of special interest since both hemispheres comprise a complex variety of different functions, and therefore, lateralization of lesions may result in different disabilities. In ischemic stroke, worse functional outcome has been reported in left hemispheric as compared to right-sided ischemia [3]. Contrarily, in $\mathrm{ICH}$, higher mortality rates at 3 months have recently been demonstrated for right-sided ICH upon a sub-analysis of the INTERACT trial, while functional outcome at 3 months was not significantly different among left- and right-sided ICH [4].

However, these analyses did not sufficiently address the baseline confounding variables, possibly influencing the reported results. Moreover, influence of site of ICH (lobar vs. deep) in relation to hemispheric location has not been linked to long-term functional outcome. This study investigated whether hemispheric location and site of ICH is associated with outcome measures - specifically long-term mortality and functional outcome - after spontaneous supratentorial ICH.

\section{Methods}

\section{Patient Selection}

The study was approved by the Institutional Review Board of the University of Erlangen-Nuremberg. Informed consent was obtained from all patients or legal representatives. Based on a prospective hospital registry, we initiated a retrospective analysis including patients with spontaneous ICH who were admitted to the Department of Neurology between January 2006 and August 2014. A total of 831 patients with supratentorial ICH were analyzed. Patients with infratentorial ICH and secondary ICH, for example, trauma, arteriovenous malformations, tumor, or ICH after acute thrombolysis or coagulopathy were excluded from the study. For 94 patients, information on long-term functional outcome was not available.

\section{Data Collection and Outcome Analysis}

As described previously, we retrieved demographic and clinical baseline characteristics from our prospective hospital registry and institutional databases [5, 6]. We evaluated mortality and functional outcome by standardized mailed questionnaires and semi-quantitative phone interviews 12 months after onset of ICH. Functional outcome was assessed using the modified Rankin Scale (mRS) score [7]. Favorable outcome was defined as mRS $0-3$, excellent outcome as mRS $0-1$, and unfavorable outcome as mRS 4-6.
Imaging

Patients with spontaneous ICH were identified by cranial imaging using CT (SOMATOM VolumeZoom or SOMATOM Definition AS+, Siemens Healthcare, Germany). CT scans were evaluated independently by 2 neuroradiologists. Hemorrhage location was scored as either deep or lobar. ICH volume was estimated according to the formula of ellipsoids $[8,9]$. Hematoma growth ( $>33 \%$ of initial ICH volume) was assessed by CT scan at approximately $<24 \pm 6 \mathrm{~h}$ after primary imaging [10]. Intraventricular hemorrhage (IVH) was graded using the Graeb score [11].

\section{Statistics}

Statistical analyses were performed using IBM $^{\circledR}$ SPSS $^{\circledR}$ (Statistics version 21, Chicago, IL, USA). Continuous variables were tested for distribution using the Kolmogorov-Smirnov test. Normally distributed data are presented as mean \pm SD and compared using one-way analysis of variance, non-normally distributed data are presented as median and interquartile range and were compared using the Mann-Whitney $U$ test. The chi-square test was used to compare dichotomized variables. Statistical significance was assumed for a $p$ value of $<0.05$ upon 2 -sided testing. A trend toward significance was defined for a $p$ value of $<0.1$. All analyses were calculated as complete case analyses, and missing variables (missing data of all investigated parameters was $<5 \%$ ) were evaluated as appropriate by this methodology [12]. A total of 94 patients were excluded only from analyses on functional outcome as there were no follow-up information on outcome measures available at 1 year. Online supplemental Table I (for all online suppl. material, see www.karger.com/doi/10.1159/000454775) displays the baseline characteristics of these patients who were lost to follow-up dichotomized by ICH location. To adjust for imbalances in baseline characteristics, a propensity score matching using a balanced, parallel, 1:1 ratio nearest-neighbor approach was conducted in which parameters showing a statistical trend in univariate analysis were taken into consideration $(p<$ $0.1)$ [6].

\section{Results}

\section{Baseline Characteristics}

Of 831 patients with supratentorial $\mathrm{ICH}$, there were 429 (51.6\%) with left-sided (203 deep and 226 lobar) and 402 (48.4\%) with right-sided (201 deep and 201 lobar) ICH. When comparing baseline characteristics of patients with left vs. right $\mathrm{ICH}$, there were significant differences in the proportion of patients with prior use of antiplatelets (108/424 [25.2\%] in left ICH vs. $138 / 396$ [34.3\%] in right $\mathrm{ICH} ; p=0.003)$, presence and extent of IVH (IVH: 192/427 [44.8\%] in left vs. $213 / 402$ [52.9\%] in right ICH; $p=0.017$; Graeb score: 0 [0-4] in left vs. $1[0-5]$ in right $\mathrm{ICH} ; p=0.017$ ) as well as a statistical trend toward a history of prior ischemic stroke (63/429 [8.9\%] in left vs. 79/402 [19.7] in right $\mathrm{ICH} ; p=0.057)$, all in disfavor of right hemispheric ICH (Table 1). 
Table 1. Admission status, demographic, neuroradiological, and treatment characteristics as well as complications of patients with supratentorial spontaneous ICH left vs. right

\begin{tabular}{|c|c|c|c|}
\hline & ICH left $(n=429)$ & $\mathrm{ICH}$ right $(n=402)$ & $p$ value \\
\hline \multicolumn{4}{|c|}{ Demographic and clinical characteristics } \\
\hline Gender*, female & $199(46.4)$ & $177(44.0)$ & 0.495 \\
\hline Age $^{\dagger}$, years & $70.2 \pm 12.9$ & $71.5 \pm 12.0$ & 0.138 \\
\hline Pre-mRS $\neq$ & $0(0-2)$ & $1(0-2)$ & 0.267 \\
\hline Congestive heart disease* & $68(15.9)$ & $64(15.9)$ & 0.978 \\
\hline Hypertension* & $354(82.5)$ & $327(81.3)$ & 0.660 \\
\hline Diabetes* & $106(24.7)$ & $106(26.4)$ & 0.583 \\
\hline Hypercholesterolemia* & $143(33.3)$ & $120(29.9)$ & 0.281 \\
\hline Ischemic stroke* & $63(14.7)$ & $79(19.7)$ & 0.057 \\
\hline Hemorrhagic stroke* & $38(8.9)$ & $32(8.0)$ & 0.642 \\
\hline Myocardial infarction* & $59(13.8)$ & $54(13.4)$ & 0.893 \\
\hline Alcoholics* & $57(13.3)$ & $48(11.9)$ & 0.559 \\
\hline Smoking* & $104(24.2)$ & $99(24.6)$ & 0.887 \\
\hline Antiplatelets* & $108(25.2)$ & $138(34.3)$ & 0.003 \\
\hline Atrial fibrillation* & $84(19.6)$ & $91(22.6)$ & 0.280 \\
\hline Oral anticoagulation* & $81(18.9)$ & $94(23.4)$ & 0.112 \\
\hline \multicolumn{4}{|l|}{ Hemorrhage characteristics } \\
\hline Location basalganglia* & $203(47.3)$ & $201(50.0)$ & 0.440 \\
\hline Location lobar* & $226(52.7)$ & $201(50.0)$ & 0.440 \\
\hline Initial $\mathrm{ICH}$ volume ${ }^{\dagger}, \mathrm{cm}^{3}$ & $29.9 \pm 35.7$ & $32.5 \pm 38$ & 0.317 \\
\hline Hematoma growth* & $40(9.3)$ & $34(8.5)$ & 0.662 \\
\hline $\mathrm{IVH}^{*}$ & $192(44.8)$ & $213(52.9)$ & 0.017 \\
\hline Graeb score ${ }^{\ddagger}$ & $0(0-4)$ & $1(0-5)$ & 0.017 \\
\hline Midlineshift $^{\dagger}, \mathrm{mm}$ & $4.23 \pm 5.6$ & $4.6 \pm 5.7$ & 0.349 \\
\hline \multicolumn{4}{|l|}{ Admission status } \\
\hline $\mathrm{GCS}^{\ddagger}$ & $13(6-15)$ & $13(5-15)$ & 1.0 \\
\hline NIHSS ${ }^{\ddagger}$ & $14(6-25)$ & $14(5-27)$ & 0.797 \\
\hline \multicolumn{4}{|l|}{ Treatment characteristics } \\
\hline EVD* & $104(24.2)$ & $115(28.6)$ & 0.154 \\
\hline Duration of $\mathrm{EVD}^{\dagger}$, days & $2.32 \pm 4.9$ & $2.82 \pm 6.5$ & 0.217 \\
\hline Ventilation* & $168(39.2)$ & $174(43.3)$ & 0.226 \\
\hline Duration of ventilation ${ }^{\dagger}$, days & $4.28 \pm 8.1$ & $5.23 \pm 10$ & 0.137 \\
\hline Tracheotomy* & $65(15.2)$ & $64(15.9)$ & 0.764 \\
\hline \multicolumn{4}{|l|}{ Complications } \\
\hline Pneumonia* & $135(31.5)$ & $141(35.1)$ & 0.269 \\
\hline Sepsis* & $71(16.6)$ & $66(16.4)$ & 1.000 \\
\hline Ventriculitis* & $4(0.9)$ & $6(1.5)$ & 0.535 \\
\hline Length of stay ${ }^{\dagger}$, days & $11.69 \pm 9.6$ & $12.34 \pm 10.5$ & 0.356 \\
\hline
\end{tabular}

ICH, intracerebral hemorrhage; CCT, cerebral computed tomography; IVH, intraventricular hemorrhage; EVD, external ventricular drain; mRS, modified Rankin Scale; GCS, Glasgow Coma Scale; NIHSS, National Institutes of Health Stroke Scale; IQR, interquartile range.

${ }^{*} n(\%),{ }^{\dagger}$ mean $\pm \mathrm{SD},{ }^{\ddagger}$ median ((IQR 25 th-75th percentile).

Regarding lobar ICH location, there were overall similar findings among patients with left and right hemispheric ICH (Table 2). However, the presence and extent of IVH were increased in right-sided ICH (IVH: 70/225 [30.9\%] in lobar left ICH vs. 85/201 [42.3\%] in lobar right $\mathrm{ICH} ; p=0.015$; Graeb score: 0 [0-2] in lobar left vs. 0
[0-3] in lobar right ICH; $p=0.030)$. The number of male patients tended to be lesser (119/226 [52.7\%] in lobar left ICH vs. 89/201 [44.3\%] in lobar right ICH; $p=0.084)$, and a more frequent use of oral anticoagulation (40/226 [17.7\%] in lobar left ICH vs. 49/201 [24.4\%] in lobar right $\mathrm{ICH} ; p=0.09$ ) was observed in right-sided ICH (Table 2). 
Table 2. Admission status, demographic, neuroradiological, and treatment characteristics as well as complications of patients with lobar/ deep ICH left vs. right

\begin{tabular}{|c|c|c|c|c|c|c|}
\hline & $\begin{array}{l}\text { Lobar left ICH } \\
(n=226)\end{array}$ & $\begin{array}{l}\text { Lobar right ICH } \\
(n=201)\end{array}$ & $p$ value & $\begin{array}{l}\text { Deep left ICH } \\
(n=203)\end{array}$ & $\begin{array}{l}\text { Deep right ICH } \\
(n=201)\end{array}$ & $p$ value \\
\hline \multicolumn{7}{|c|}{ Demographic and clinical characteristics } \\
\hline $\mathrm{Age}^{\dagger}$, years & $71.3 \pm 13.2$ & $72.5 \pm 12.3$ & 0.349 & $68.9 \pm 12.5$ & $68.8 \pm 11.7$ & 0.202 \\
\hline Pre-mRS ${ }^{\ddagger}$ & $1(0-2)$ & $1(0-2)$ & 0.838 & $0(0-1)$ & $1(0-2)$ & 0.040 \\
\hline Congestive heart disease* & $42(18.6)$ & $35(17.4)$ & 0.753 & $26(12.8)$ & $29(14.4)$ & 0.635 \\
\hline Hypercholesterolemia* & $81(33.3)$ & $71(29.9)$ & 0.911 & $62(30.5)$ & $49(24.4)$ & 0.165 \\
\hline Ischemic stroke* & $32(14.2)$ & $34(16.9)$ & 0.432 & $31(15.3)$ & $45(22.4)$ & 0.067 \\
\hline Hemorrhagic stroke* & $28(12.4)$ & $20(10.0)$ & 0.426 & $10(4.9)$ & $12(6.0)$ & 0.644 \\
\hline Myocardial infarction* & $35(15.5)$ & $27(13.4)$ & 0.548 & $24(11.8)$ & $27(13.4)$ & 0.626 \\
\hline Alcoholics* & $24(10.6)$ & $48(23.9)$ & 0.001 & $33(16.3)$ & $27(13.4)$ & 0.423 \\
\hline Smoking* & $56(24.8)$ & $49(24.4)$ & 0.920 & $48(23.6)$ & $50(24.9)$ & 0.777 \\
\hline Initial ICH volume ${ }^{\dagger}, \mathrm{cm}^{3}$ & $36.8 \pm 39.9$ & $40.9 \pm 42.9$ & 0.312 & $22.3 \pm 28.5$ & $24.3 \pm 30.3$ & 0.509 \\
\hline Hematoma growth* & $14(6.2)$ & $17(8.5)$ & 0.368 & $26(12.8)$ & $17(8.5)$ & 0.156 \\
\hline $\mathrm{IVH}^{*}$ & $70(30.9)$ & $85(42.3)$ & 0.015 & $122(60.0)$ & $128(63.7)$ & 0.458 \\
\hline Graeb-score f & $0(0-2)$ & $0(0-3)$ & 0.030 & $2(0-6)$ & $3(0-8)$ & 0.317 \\
\hline Midlineshift ${ }^{\dagger}, \mathrm{mm}$ & $4.4 \pm 6.3$ & $4.8 \pm 6.3$ & 0.564 & $4.0 \pm 4.8$ & $4.5 \pm 5.0$ & 0.409 \\
\hline \multicolumn{7}{|l|}{ Admission status } \\
\hline $\mathrm{GCS}^{\ddagger}$ & $13(7-15)$ & $13(5-15)$ & 0.730 & $12(5-14)$ & $12(5-14)$ & 0.624 \\
\hline NIHSS ${ }^{\ddagger}$ & $12(4-23)$ & $11(3-26)$ & 0.989 & $17(8-28)$ & $16(9-29)$ & 0.889 \\
\hline \multicolumn{7}{|l|}{ Treatment characteristics } \\
\hline $\mathrm{EVD}^{*}$ & $31(13.7)$ & $31(15.4)$ & 0.617 & $73(13.7)$ & $84(15.4)$ & 0.229 \\
\hline Duration of $\mathrm{EVD}^{\dagger}$, days & $1.2 \pm 3.6$ & $1.4 \pm 3.9$ & 0.586 & $3.6 \pm 5.8$ & $4.3 \pm 8.1$ & 0.347 \\
\hline
\end{tabular}

ICH, intracerebral hemorrhage; CCT, cerebral computed tomography; IVH, intraventricular hemorrhage; EVD, external ventricular drain; mRS, modified Rankin Scale; GCS, Glasgow Coma Scale; NIHSS, National Institutes of Health Stroke Scale; IQR, interquartile range.

${ }^{*} \mathrm{n}(\%),{ }^{\dagger}$ mean $\pm \mathrm{SD},{ }^{\ddagger}$ median (IQR 25 th-75th percentile).

Comparison of hemispheric location in patients with deep ICH also revealed very similar findings (Table 2). Indeed, patients with right-sided ICH showed a significantly poorer pre-existing clinical status (mRS prior to ICH: $0[0-1]$ in deep left ICH vs. $1[0-2]$ in deep right $\mathrm{ICH} ; p=0.04)$ alongside a statistical trend toward a history of prior ischemic stroke (31/203 [15.3\%] in deep left ICH vs. 45/201 [22.4\%] in deep right $\mathrm{ICH} ; p=0.067$ ), as compared to left hemispheric deep ICH patients.
Long-Term Functional Outcome in Left versus Right Hemispheric ICH - Unadjusted Analysis

Long-term functional outcome of the entire cohort is shown in Figure 1. There was no difference in long-term mortality among patients with left vs. right ICH (168/375 [44.8\%] in left ICH vs. $163 / 362$ [45\%] in right ICH; $p=$ 0.950 ), and the proportion of patients with favorable vs. unfavorable outcome also did not differ among patients with left vs. right hemispheric ICH (mRS 0-3: 142/375 [37.9\%] in left ICH vs. $117 / 362$ [32.3\%] in right ICH; $p=$ 


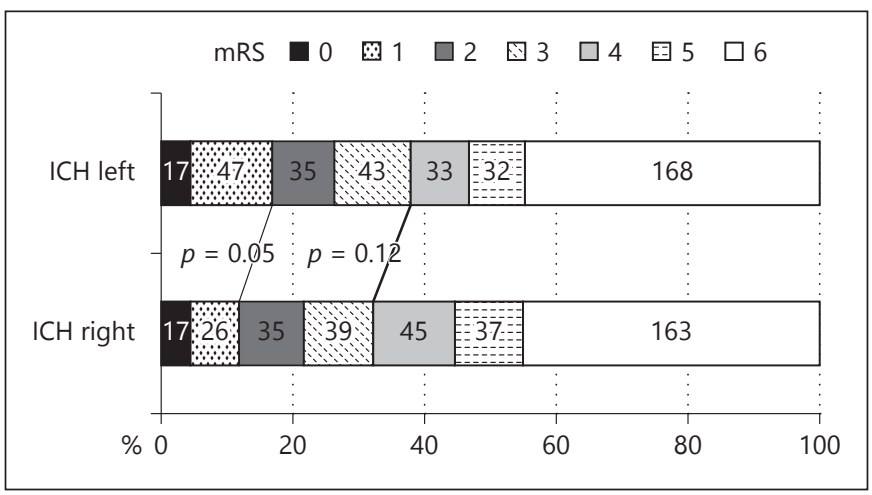

Fig. 1. Distribution of long-term functional outcome at 1 year after $\mathrm{ICH}$. A favorable functional outcome (mRS 0-3 vs. 4-6) is shown as a bold line. An excellent functional outcome (mRS 0-1 vs. 2-6) is shown as a thin line.

0.115). However, the proportion of patients with excellent outcome was significantly higher in patients with left-sided ICH (mRS 0-1: 64/375 [17.1\%] in left ICH vs. $43 / 362$ [11.9\%] in right ICH; $p=0.046$ ) (Fig. 1; online supplemental Table II for various dichotomized outcome analyses [13]).

Outcome analysis of patients with deep ICH revealed no significant differences in the proportion of patients with favorable vs. unfavorable outcome among patients with left and right hemispheric ICH (mRS 0-3: 65/176 [36.9\%] in left ICH vs. 57/184 [31.0\%] in right ICH; $p=$ 0.233; mRS 0-1: 24/176 [13.6\%] in left ICH vs. $17 / 184$ [9.2\%] in right ICH; $p=0.189$; online suppl. Fig. I). Outcome analysis of patients with lobar ICH revealed no significant differences in the proportion of patients with favorable vs. unfavorable outcome among patients with left and right hemispheric ICH (mRS 0-3: 77/199 [38.7\%] in left ICH vs. $60 / 178$ [33.7\%] in right $\mathrm{ICH} ; p=0.315$; mRS 0-1: 40/199 [20.1\%] in left ICH vs. 26/178 [14.6\%] in right $\mathrm{ICH} ; p=0.161$; online suppl. Fig. II).

\section{Long-Term Functional Outcome in Propensity Score Matched Cohort - Adjusted Analysis}

To account for imbalances in baseline characteristics (Table 1, i.e., prior use of antiplatelets, history of ischemic stroke, presence and extent of IVH), we performed a propensity score matching that provided evenly balanced cohorts (overall: $n=360$ for left and right-sided ICH, see online supplemental Table III, $n=187$ for lobar left and $n=$ 178 for lobar right as well as $n=173$ for deep left and $n=182$ for deep right ICH, see online supplemental Table IV). Neither mortality nor favorable or excellent long-term functional outcome was different among the overall pro-

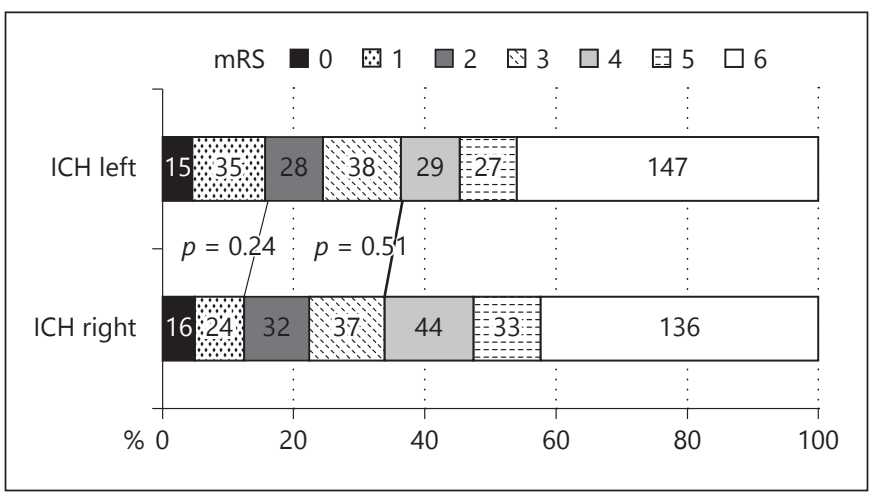

Fig. 2. Distribution of long-term functional outcome in the propensity score matched cohort at 1 year after $\mathrm{ICH}$. A favorable functional outcome ( $\mathrm{mRS} 0-3$ vs. $4-6$ ) is shown as a bold line. An excellent functional outcome (mRS $0-1$ vs. $2-6$ ) is shown as a thin line.

pensity score matched cohort of patients with left-vs. rightsided ICH (mortality: 147/319 [46.1\%] in left ICH vs. $136 / 322$ [42.2\%] in right $\mathrm{ICH} ; p=0.33$; mRS 0-3: 116/319 [36.4\%] in left ICH vs. 109/322 [33.9\%] in right ICH; $p=$ $0.51 ; \mathrm{mRS} 0-1: 50 / 319$ [15.7\%] in left ICHvs. 40/322 [12.4\%] in right $\mathrm{ICH} ; p=0.24$; Fig. 2 ; online suppl. Table V).

In patients with deep $\mathrm{ICH}$, there were no significant differences in outcome measures (mortality: 69/151 [45.7\%] in deep left ICH vs. 60/165 [36.4\%] in deep right $\mathrm{ICH} ; p=0.09 ; \mathrm{mRS} 0-3: 53 / 151$ [35.1\%] in deep left ICH vs. $53 / 165[32.1 \%]$ in deep right $\mathrm{ICH} ; p=0.58$; $\mathrm{mRS} 0-1$ : $17 / 151$ [11.3\%] in deep left ICH vs. 16/165 [9.7\%] in deep right ICH; $p=0.65$; online suppl. Fig. III). In patients with lobar ICH, there were no differences in outcome measures (mortality: 78/168 [46.4\%] in lobar left ICH vs. $76 / 157$ [48.4\%] in lobar right ICH; $p=0.72$; mRS $0-3$ : $63 / 168$ [37.5\%] in lobar left ICH vs. 56/157 [35.7\%] in lobar right ICH; $p=0.73$; $\mathrm{mRS} 0-1: 33 / 168$ [19.6\%] in lobar left ICH vs. $24 / 157$ [15.3\%] in lobar right ICH; $p=$ 0.30; online suppl. Fig. IV).

\section{Discussion}

This study investigated the impact of hemispheric location and site of ICH on clinical end points in a large cohort of patients with spontaneous supratentorial ICH. In essence, significant and clinically relevant differences in baseline characteristics existed for hemispheric location and site of ICH in disfavor of patients with right-sided ICH. However, significant differences in mortality and long-term functional outcome were not observed among patients with left vs. right hemispheric ICH. Given the 
implications for both invasive treatment as well as treatment restrictions which were raised by previous studies that reported on differences in ICH locations, it appears important to provide evidence that no outcome differences were observed. Some aspects emerge from the data.

First, there are quite a few studies that deal with the issue of laterality of stroke lesions and its impact on patients' long-term functional outcome and mortality after ischemic stroke [14-17]. Regarding ICH, the largest study recently published was a post-hoc analysis of the INTERACT trial reporting on increased rates of mortality in right-sided ICH [4]. However, the methodological approach of this study lacked a strong enough statistical design to rule out baseline confounders possibly accounting for the described mortality differences. Moreover, only short-term outcome was assessed and the ethnic decent of included patients undermined extrapolation of these findings to European Caucasians. Furthermore, INTERACT included about $90 \%$ of deep ICH and reported an unrepresentatively low rate of mortality (about $10 \%$ ), usually amounting up to $40 \%$ at 3 months [18]. We have correlated hemispheric location and site of ICH to long-term functional outcome using established statistical approaches to minimize bias. As demonstrated for ischemic stroke [15], and in line with findings from Sato et al. [4] in ICH, we were unable to verify differences in outcome measures among patients with left- vs. right-sided ICH.

Second, while it does not appear surprising that adjusted outcome analysis revealed no differences among left and right ICH for the overall population, differences were expected in the subgroup analyses regarding the site of ICH, specifically in lobar ICH [19]. On the one hand, from a pathophysiological point of view, hemispheric differences were not expected in deep ICH as corticospinal tracts and projection neurons are more affected [20]. On the other hand, given the various cognitive and executive functions located within cerebral lobes, outcome differences may be anticipated in lobar ICH when comparing left- vs. right-sided bleedings $[21,22]$. In cerebral ischemia, such differences have been reported for malignant middle cerebral artery infarctions (e.g., speech impairment in left-sided vs. cognitive impairment and depression in right-sided infarctions [23-25]). However, we were not able to detect possible outcome differences in lobar ICH between left and right hemispheric ICH, an aspect that either reflects very small patient numbers or insufficient discriminatory power of the mRS in evaluation of cognitive and other end points [7].

Third, the reason for differences in baseline characteristics among left- and right-sided ICH need to be discovered, and also for their crystallization to predominantly occur in disfavor of right-sided ICH. Although not significant, one explanation may be the gender distribution with more male patients - having usually more comorbidities than women $[26,27]$ - in the group of right-sided ICH. Only systematically designed prospective registries including longitudinal cranial imaging and careful assessment of lifestyle factors may be able to address whether additional physiological aspects may be the bottom of different comorbidities among left- and right-sided stroke [3].

Limitations of the present study are its retrospective and single-center design and - compared to INTERACT - fewer patient numbers. Furthermore, we have only assessed functional outcome and mortality and did not obtain cognitive or quality-of-life end points to possibly detect subtle differences not displayed in dichotomized mRS outcome. Moreover, long-term complications, such as new ischemic or hemorrhagic stroke and their secondary complications, have not been assessed as our observational study design did not allow to obtain valid information on such complications.

\section{Conclusion}

Long-term functional outcome after ICH most likely is not influenced by hemispheric location. It remains questionable whether data from the INTERACT trial have been affected by confounding baseline variables. Nonetheless, further analyses, especially those of lobar ICHs, are warranted since differences in functional outcome in respect to specific lesions are conceivable.

\section{Acknowledgments}

We would like to thank Petra Burkardt for helping with data acquisition.

\section{Sources of Funding}

The study was partially funded by the ELAN-program (12-01-041; FSt 56610036) of the Friedrich-Alexander University ErlangenNuremberg, Germany.

\section{Disclosure Statement}

All authors have no conflicts of interest to report and have read the article, agree with the contents, and approved the final version of the article. 


\section{References}

1 Flaherty ML, Haverbusch M, Sekar P, Kissela B, Kleindorfer D, Moomaw CJ, Sauerbeck L, Schneider A, Broderick JP, Woo D: Longterm mortality after intracerebral hemorrhage. Neurology 2006;66:1182-1186.

2 Gonzalez-Perez A, Gaist D, Wallander MA, McFeat G, Garcia-Rodriguez LA: Mortality after hemorrhagic stroke: data from general practice (The Health Improvement Network). Neurology 2013;81:559-565.

3 Hedna VS, Bodhit AN, Ansari S, Falchook $\mathrm{AD}$, Stead L, Heilman KM, Waters MF: Hemispheric differences in ischemic stroke: is left-hemisphere stroke more common? J Clin Neurol 2013;9:97-102.

4 Sato S, Heeley E, Arima H, Delcourt C, Hirakawa Y, Pamidimukkala V, Li Z, Tao Q, Xu Y, Hennerici MG, Robinson T, Tzourio C, Lindley RI, Chalmers J, Anderson CS; INTERACT Investigators, Anderson CS, Huang Y, Wang JG, Arima H, Neal B, Peng B, Heeley E, Skulina C, Parsons MW, Kim JS, Tao QL, Li YC, Jiang JD, Tai LW, Zhang LJ, Xu E, Cheng Y, Heritier S, Morgenstern LB, Chalmers J: Higher mortality in patients with right hemispheric intracerebral haemorrhage: INTERACT1 and 2. J Neurol Neurosurg Psychiatry 2015;86:1319-1323.

5 Kuramatsu JB, Bobinger T, Volbers B, Staykov D, Lucking $\mathrm{H}$, Kloska SP, Kohrmann M, Huttner HB: Hyponatremia is an independent predictor of in-hospital mortality in spontaneous intracerebral hemorrhage. Stroke 2014;45:1285-1291.

6 Kuramatsu JB, Gerner ST, Schellinger PD, Glahn J, Endres M, Sobesky J, Flechsenhar J, Neugebauer H, Juttler E, Grau A, Palm F, Rother J, Michels P, Hamann GF, Huwel J, Hagemann G, Barber B, Terborg C, Trostdorf F, Bazner H, Roth A, Wohrle J, Keller M, Schwarz M, Reimann G, Volkmann J, Mullges W, Kraft P, Classen J, Hobohm C, Horn M, Milewski A, Reichmann H, Schneider H, Schimmel E, Fink GR, Dohmen C, Stetefeld $\mathrm{H}$, Witte $\mathrm{O}$, Gunther A, Neumann-Haefelin T, Racs AE, Nueckel M, Erbguth F, Kloska SP, Dorfler A, Kohrmann M, Schwab S, Huttner HB: Anticoagulant reversal, blood pressure levels, and anticoagulant resumption in patients with anticoagulation-related intracerebral hemorrhage. JAMA 2015;313: 824-836.
7 Rankin J: Cerebral vascular accidents in patients over the age of 60 . I. General considerations. Scott Med J 1957;2:127-136.

8 Kothari RU, Brott T, Broderick JP, Barsan WG, Sauerbeck LR, Zuccarello M, Khoury J: The ABCs of measuring intracerebral hemorrhage volumes. Stroke 1996;27:1304-1305.

9 Huttner HB, Steiner T, Hartmann M, Kohrmann M, Juettler E, Mueller S, Wikner J, Meyding-Lamade U, Schramm P, Schwab S, Schellinger PD: Comparison of ABC/2 estimation technique to computer-assisted planimetric analysis in warfarin-related intracerebral parenchymal hemorrhage. Stroke 2006; 37:404-408.

10 Brott T, Broderick J, Kothari R, Barsan W, Tomsick T, Sauerbeck L, Spilker J, Duldner J, Khoury J: Early hemorrhage growth in patients with intracerebral hemorrhage. Stroke 1997;28:1-5.

11 Graeb DA, Robertson WD, Lapointe JS, Nugent RA, Harrison PB: Computed tomographic diagnosis of intraventricular hemorrhage. Etiology and prognosis. Radiology 1982;143:91-96.

12 Groenwold RH, Donders AR, Roes KC, Harrell FE Jr, Moons KG: Dealing with missing outcome data in randomized trials and observational studies. Am J Epidemiol 2012;175: 210-217.

13 Uyttenboogaart M, Stewart RE, Vroomen PC, De Keyser J, Luijckx GJ: Optimizing cutoff scores for the Barthel index and the modified Rankin scale for defining outcome in acute stroke trials. Stroke 2005;36:1984-1987.

14 Wade DT, Hewer RL, Wood VA: Stroke: influence of patient's sex and side of weakness on outcome. Arch Phys Med Rehabil 1984;65: 513-516.

15 Aszalos Z, Barsi P, Vitrai J, Nagy Z: Lateralization as a factor in the prognosis of middle cerebral artery territorial infarct. Eur Neurol 2002;48:141-145

16 Fink JN, Frampton CM, Lyden P, Lees KR: Does hemispheric lateralization influence functional and cardiovascular outcomes after stroke?: an analysis of placebo-treated patients from prospective acute stroke trials. Stroke 2008;39:3335-3340.

17 Algra A, Gates PC, Fox AJ, Hachinski V, Barnett HJ: Side of brain infarction and longterm risk of sudden death in patients with symptomatic carotid disease. Stroke 2003;34: 2871-2875.

18 van Asch CJ, Luitse MJ, Rinkel GJ, van der Tweel I, Algra A, Klijn CJ: Incidence, case fatality, and functional outcome of intracerebral haemorrhage over time, according to age, sex, and ethnic origin: a systematic review and meta-analysis. Lancet Neurol 2010;9:167176

19 Castellanos M, Leira R, Tejada J, Gil-Peralta A, Davalos A, Castillo J: Predictors of good outcome in medium to large spontaneous supratentorial intracerebral haemorrhages. J Neurol Neurosurg Psychiatry 2005;76:691695.

20 Aguilar MI, Brott TG: Update in intracerebral hemorrhage. Neurohospitalist 2011;1:148159 .

21 Tveiten A, Ljostad U, Mygland A, Naess H: Functioning of long-term survivors of firstever intracerebral hemorrhage. Acta Neurol Scand 2014;129:269-275.

22 Smith EE, Gurol ME, Eng JA, Engel CR, Nguyen TN, Rosand J, Greenberg SM: White matter lesions, cognition, and recurrent hemorrhage in lobar intracerebral hemorrhage. Neurology 2004;63:1606-1612.

23 Walz B, Zimmermann C, Bottger S, Haberl RL: Prognosis of patients after hemicraniectomy in malignant middle cerebral artery infarction. J Neurol 2002;249:1183-1190.

24 Benejam B, Sahuquillo J, Poca MA, Frascheri L, Solana E, Delgado P, Junque C: Quality of life and neurobehavioral changes in survivors of malignant middle cerebral artery infarction. J Neurol 2009;256:1126-1133.

25 Schmidt H, Heinemann T, Elster J, Djukic M, Harscher S, Neubieser K, Prange H, Kastrup A, Rohde V: Cognition after malignant media infarction and decompressive hemicraniectomy - a retrospective observational study. BMC Neurol 2011;11:77.

26 Saleem Y, DeFina LF, Radford NB, Willis BL, Barlow CE, Gibbons LW, Khera A: Association of a favorable cardiovascular health profile with the presence of coronary artery calcification. Circ Cardiovasc Imaging 2014; 8:pii:e001851.

$27 \mathrm{Hu}$ YZ, Wang JW, Luo BY: Epidemiological and clinical characteristics of 266 cases of intracerebral hemorrhage in Hangzhou, China. J Zhejiang Univ Sci B 2013;14:496-504. 